\title{
Feasibility of Algal Systems for Sustainable Wastewater Treatment
}

\author{
Thinesh Selvaratnam ${ }^{1}$, Ambica Pegallapati ${ }^{2}$, Felly Montelya ${ }^{1}$, Gabriela Rodriguez ${ }^{1}$, \\ Nagamany Nirmalakhandan* ${ }^{1}$, Peter J. Lammers ${ }^{3}$, and Wayne van Voorhies ${ }^{4}$ \\ ${ }^{1}$ Civil Engineering Department, New Mexico State University, Las Cruces, NM 88003, USA \\ ${ }^{2}$ Argonne National Laboratory, Argonne, IL 60439, USA \\ ${ }^{3}$ Energy Research Laboratory, New Mexico State University, Las Cruces, NM 88003, USA \\ 4Biochemistry Dept. New Mexico State University, Las Cruces, NM 88003, USA \\ *Corresponding author, email: nkhandan@nmsu.edu; phone: 1 (575) 6465378
}

\begin{abstract}
This paper proposes cultivation of algae in urban wastewaters as a sustainable approach for removing the nutrients from the wastewaters and generating energy from the biomass. The theoretical rationale of this proposal is that, the algal systems can produce nearly double the biomass per unit nutrient intake than bacterial systems and can generate nearly $20 \%$ more net energy. Preliminary experimental results are presented to demonstrate that a thermotolerant and acidophilic algal strain evaluated in this study-Galdieria sulphuraria, can grow well in primary settled urban wastewaters and can reduce nutrient levels to regulatory discharge levels at reasonable rates. Nutrient removal rates found in this study (4.70 to 5.0 $\mathrm{mg} \mathrm{L}^{-1} \mathrm{~d}^{-1}$ of nitrogen and 1.5 to $1.7 \mathrm{mg} \mathrm{L}^{-1} \mathrm{~d}^{-1}$ of phosphate) are comparable to those by traditional methods.
\end{abstract}

KEYWORDS: Algal wastewater treatment; nitrogen removal; phosphate removal; Galdieria sulphuraria; thermo-tolerant acidophilic strains.

\section{INTRODUCTION}

Current state of urban wastewater treatment

Urban wastewaters are rich in organic carbon, nitrogen $(\mathrm{N})$, phosphorus $(\mathrm{P})$, and other minerals, which are required to be removed prior to discharge into receiving waters. 
Excessive loading of receiving waters with organic carbon and nutrients can lead to depletion of dissolved oxygen, toxicity to aquatic life, and eutrophication. In fact, urban wastewater discharges with excess nutrients are among the top causes of impairment of designated use in numerous receiving water bodies in the US and around the world.

Typical wastewater treatment plants (WWTPs) equipped with secondary treatment processes are able to meet the discharge levels for organic carbon (quantified as Biochemical Oxygen Demand, BOD), but fail to meet the discharge levels for $\mathrm{N}$ and P [1]. To meet the discharge limits for both $\mathrm{N}$ and $\mathrm{P}$, WWTPs are now required to add tertiary treatment systems to treat the secondary effluent. Biological Nutrient Removal (BNR) is one of the options for tertiary treatment of urban wastewaters, where, ammoniacal nitrogen $\left(\mathrm{NH}_{3}-\mathrm{N}\right)$ is converted to nitrogen gas and phosphorus is removed by entrapping in the biomass. However, BNR processes are immensely energy intensive, accounting for 60-80\% of the total energy requirement for wastewater treatment [2]. For example, in a 5.5 MGD plant, the measured energy consumption for aeration averaged $1.48 \mathrm{~kW}-\mathrm{hr}$ per $\mathrm{kg}$ BOD removal; $13.44 \mathrm{~kW}$-hr per total $\mathrm{N}$ removal; and $6.44 \mathrm{~kW}$-hr per total $\mathrm{P}$ removal [3].

In addition to the energy demand, by-products and side-streams from current wastewater treatment technologies, result in additional direct and indirect environmental burden. For instance, the traditional activated sludge process for BOD removal typically generates 0.45 $\mathrm{kg}$ waste biomass per $\mathrm{kg}$ BOD removed, disposal of which contributes to nearly $50 \%$ of the cost of operating a WWTP. With current trends in growth of population and their shifts toward urban centers, increasing numbers of WWTPs would be required to add tertiary treatment to meet nutrient discharge standards; with limited fossil fuel-based energy supplies. As a result the traditional urban wastewater treatment technologies are thus deemed unsustainable.

Recognizing the above concerns, many researchers have been striving to develop energyefficient and sustainable technologies that could minimize or avert the energy consumption and avoid the emission-, eutrophication-, and acidification-potentials associated with the production of that energy. 


\section{Pathways for sustainable urban wastewater treatment}

The idea of transforming WWTPs as a net energy producer rather than net energy user, has been one of the hot topics of research in recent times. Since urban wastewater itself contains internal energy of $6.3-7.6 \mathrm{~kJ} \mathrm{~L}^{-1}$ [4], it seems logical to harvest this energy rather than expending energy to dissipate it. Several available or emerging technologies have been shown to be capable of recovering some of the energy content of wastewaters in one form or another. Anaerobic digestion, for example, is a well-established process for converting that energy content to methane; dark fermentation has the potential to convert that energy to a more efficient and cleaner energy carrier- hydrogen; microbial fuel cells have been shown to convert that energy directly to electricity at even higher efficiency.

Recently, McCarty et al. [5] have reviewed the practical readiness of the above alternatives and concluded that anaerobic treatment could replace the traditional energy-intensive practice to treat urban wastewaters, while recovering some of its energy to produce methane for use as an energy carrier. Extending the above approach, coupling technologies that could recover the internal energy of wastewaters with those that could recover and recycle their nutrient content for beneficial use would lead to, not only sustainable but, perhaps, profitable urban wastewater treatment. A promising approach in this direction is algal-based wastewater treatment systems.

The idea of adopting microalgae for nutrient removal from wastewater has been discussed previously [6]. Several studies have shown high removal efficiencies for $\mathrm{N}$ and $\mathrm{P}$ by algal systems [7], [8]. Early efforts of Oswald [9], [10] in this area are now being revamped as a sustainable alternative for urban wastewater treatment and energy production. The premise of this approach is that, mixotrophic algal systems could be engineered to reduce organic carbon as well as nutrients in urban wastewaters to the required discharge levels and, at the same time, utilize the carbon and nutrients that are currently dissipated, to cultivate energyrich biomass as feedstock for generating gaseous or liquid biofuels. This approach could have an energy-advantage over that proposed by McCarty et al. [5] because, the algal biomass would incorporate both the internal energy of the wastewater as well as solar 
energy captured through photosynthesis.

It has been estimated that, in the traditional activated sludge process, removal of $1 \mathrm{~kg}$ of BOD would consume about $1 \mathrm{~kW}$-hr of electricity for aeration (resulting in $1 \mathrm{~kg}$ of fossil$\mathrm{CO}_{2}$ emission in the electricity generation process) and generate about $0.45 \mathrm{~kg}$ of waste biomass [11]. In contrast, $1 \mathrm{~kg}$ of BOD removed by photosynthetic oxygenation in mixotrophic algal systems requires no energy inputs and could produce enough algal biomass that can be anaerobically digested to generate methane equivalent to $1 \mathrm{~kW}$-hr of electric power [11]. Even though the waste biomass generated by the traditional activated sludge process could be anaerobically digested to recover some energy in the form of methane, the theoretical methane potential of algal biomass generated through mixotrophic cultivation, could be more than that of the biomass generated by activated sludge.

The fundamental building block for energy positive WWT is with algal systems is stoichiometric balancing. Carbon dioxide fixation via algal photosynthesis rectifies the low $\mathrm{C}: \mathrm{N}: \mathrm{P}$ ratio in untreated municipal wastewater with the high $\mathrm{C}: \mathrm{N}: \mathrm{P}$ ratio found in biomass produced during WWT. An algal process affords one-step removal of $\mathrm{C}, \mathrm{N}$ and $\mathrm{P}$ yielding discharge-ready water for re-use and substantially more biomass than activated sludge processes for conversion to energy products. Assuming the empirical formula for activated sludge as $\mathrm{C}_{5} \mathrm{H}_{7} \mathrm{O}_{2} \mathrm{~N}$, biomass production by the traditional approach can be seen to be $8.1 \mathrm{~g}$ biomass per $\mathrm{g}$ of $\mathrm{NH}_{4}-\mathrm{N}$ removed. Following the estimation method of Speece (1996) [12], this biomass production translates to a methane potential of $5.3 \mathrm{~L} \mathrm{CH}_{4} / \mathrm{g}$ of $\mathrm{N}$ removed. In comparison, assuming the empirical formula for algal biomass as $\mathrm{C}_{106} \mathrm{H}_{263} \mathrm{O}_{110} \mathrm{~N}_{16} \mathrm{P}$ [13], biomass production in an algal system can be seen to be $15.8 \mathrm{~g}$ biomass per $\mathrm{g}$ of $\mathrm{NH}_{4}-\mathrm{N}$ removed (agreeing with Ebeling et al. [14]). The methane potential of this amount of biomass can be estimated as $6.3 \mathrm{~L} \mathrm{CH}_{4}$ per $\mathrm{g}$ of $\mathrm{N}$ removed [12] which is $19 \%$ higher than that in the activated sludge process.

Even though the above comparisons favoring the algal-based systems are based on theoretical estimates and pilot scale experiments, their practical feasibility has not been fully demonstrated. Several research and development groups are currently working on various 
aspects of algal-based systems for the dual purpose of wastewater treatment and energy production. This paper presents preliminary results on two strains of a mixotrophic species, Galdieria sulphuraria, that have, until now, not been explored for this application. Unique characteristics and the rationale for selecting this species for urban wastewater treatment are discussed next.

\section{Rationale for Galdieria sulphuraria}

A unique characteristic of Galdieria sulphuraria (G. sulphuraria) is that, it is a thermotolerant acidophilic strain [15], which can thrive at $\mathrm{pH}$ of $0-4$. Such low $\mathrm{pH}$ range is beneficial in deactivating pathogens and most competitive species naturally found in wastewaters [16]. The thermophilic nature of these strains enables cultivation in closed photobioreactors which otherwise would have to be cooled. Closed photobioreactors also benefit from high $\mathrm{CO}_{2}$ utilization efficiency, minimum evaporative losses, and low crosscontamination. Potential mixotrophic nature of these strains enables higher biomass densities to be maintained to minimize the footprint and improve downstream processing efficiency. This paper presents the feasibility of cultivating two strains of G. sulphuraria, 5587.1 and 5572 in primary settled urban wastewater.

\section{MATERIALS AND METHODS}

\section{Algae strain collection and culture condition}

Two independent isolates of unicellular red algae, G. sulphuraria CCMEE 5587.1 and 5572 [15] obtained from the Culture Collection of Microorganisms from Extreme Environments (University of Oregon) were assessed in this study. Both strains were grown in an incubator (Percival, IA, USA) at $40^{\circ} \mathrm{C}$ with a $14 \mathrm{~h} / 10 \mathrm{hr}$ light/dark cycle in Standard Cyanidium medium [15] modified to contain twice the standard ammonium sulphate concentration and supplemented with the vitamin component of $f / 2$ algal medium [17]. Cultures were streaked onto agar plates and single colonies were then picked to start axenic cultures from culture plates to modified Cyanidium medium scaling up the volume to 1-L Erlenmeyer flasks. The following are the constituents of the modified Cyanidium medium: $\left(\mathrm{NH}_{4}\right)_{2} \mathrm{SO}_{4}, 2.64 \mathrm{~g} \mathrm{~L}^{-1}$; $\mathrm{KH}_{2} \mathrm{PO}_{4}, 0.27 \mathrm{~g} \mathrm{~L}^{-1} ; \mathrm{NaCl}, 0.12 \mathrm{~g} \mathrm{~L}^{-1} ; \mathrm{MgSO}_{4} .7 \mathrm{H}_{2} \mathrm{O}, 0.25 \mathrm{~g} \mathrm{~L}^{-1} ; \mathrm{CaCl}_{2} .2 \mathrm{H}_{2} \mathrm{O}, 0.07 \mathrm{~g} \mathrm{~L}^{-1}$; Nitch's Trace Element Solution, $0.5 \mathrm{~mL} ; \mathrm{FeCl}_{3}$ (solution $=0.29 \mathrm{~g} \mathrm{~L}^{-1}$ ), $1.0 \mathrm{~mL}$, and the $\mathrm{pH}$ 
adjusted to 2.5 with $10 \mathrm{~N} \mathrm{H}_{2} \mathrm{SO}_{4}$. Includes vitamin component of $\mathrm{f} / 2$ algal medium (vitamins B1, B12 and biotin).

Wastewater used in this study was collected downstream of the primary settling tank at the municipal WWTP, Las Cruces, NM. Upon collection of the sample, large solid particles were removed by gravity settling; autoclaved (at $121^{\circ} \mathrm{C}$ ); and stored at $4^{\circ} \mathrm{C}$. The clear supernatant was used in the experiments to make up the growth medium. At the beginning of each test, the inoculum was centrifuged (Sorvall Biofuge primo, Thermo Scientific, USA) and the algae pellets were re-suspended in the control set medium of the particular test and left for 24 hours at $40^{\circ} \mathrm{C}, 14 \mathrm{hr} / 10 \mathrm{hr}$ light/dark photoperiod for preadaptation. Biomass growth was quantified daily, in terms of the optical density (OD) measured with Beckman DU530 spectrophotometer (Beckman Coulter Inc., USA) at a wavelength of $750 \mathrm{~nm}$.

\section{Experimental conditions}

Four Tests (A to D) were conducted to assess the growth patterns of the two strains under two different temperature regimes; and to verify the suitability of wastewater as a growth medium. Experimental conditions adapted for assessing the two strains are summarized in Table I. Tests A and B were designed to assess and compare the performance of the two species at a constant temperature of $40^{\circ} \mathrm{C}$, while Tests $\mathrm{C}$ and $\mathrm{D}$ were designed to assess and

compare their performance under a varying diurnal temperature regime (variable: ramping from 26 to $42^{\circ} \mathrm{C}$ over a $10 \mathrm{~h}$ period) to mimic outdoor conditions. Each of these tests were run with three different growth mediums, coded as shown in Table I. Growth medium coded as 1 was used to serve as baseline for autotrophic growth, while medium Coded 2 was used to assess the heterotrophic growth. Tests A-D were run for 10 days.

Based on the findings of Tests A-D (discussed further in results), a fifth test (Test E), was run to assess nutrient removal by 5587.1 at constant temperature of $40^{\circ} \mathrm{C}$, under three different media conditions, Code 4 to 6, as described in Table I. The objective of Test E, was to check the growth and nutrient removal in both filter sterilized and non-autoclaved wastewater compared to modified cyanidium media over a period of 7 days. Filter 
sterilization of primary effluent wastewater was done with Nalgene Rapid-Flow filter units $(0.45 \mu \mathrm{m})$ (Thermo Scientific, USA).

The cultures were grown in $16 \mathrm{~mL}$ borosilicate glass tubes, capped with plastic caps and sealed with parafilm to reduce evaporative losses. Each tube was inoculated with $6 \mathrm{~mL}$ of culture and placed in the outer rim of a roller drum (New Brunswick Scientific, Eppendorf., Connecticut, USA) rotating at $16 \mathrm{rpm}$. The roller drum was housed inside an incubator (Percival, IA, USA) where the $\mathrm{CO}_{2}$ level was maintained at 2-3\% (vol/vol) throughout the experiments.

\section{Optical density measurements}

Biomass growth was quantified daily, in terms of the optical density (OD) measured with Beckman DU530 spectrophotometer (Beckman Coulter Inc., USA) at a wavelength of 750 $\mathrm{nm}$. The biomass density, was evaluated in terms of 'ash-free dry weight X' (g AFDW per L), which was correlated to OD at $750 \mathrm{~nm}$ by the following equation:

$$
X=0.54553 \times O D_{@ 750 \mathrm{~nm}}+0.022839 ; n=12 ; r^{2}=0.997
$$

\section{$N$ and $P$ measurements}

During Tests A-D, 3 of the glass tubes were removed from the drum on days 2, 5, 7 and 10; and during Test E, 3 glass tubes were removed on days 1, 3, 5 and 7 to serve as triplicates for measuring the nutrient levels. Culture samples from each tube were first centrifuged at 4,000 rpm for 10 minutes and the supernatant was diluted and analyzed. Ammonia nitrogen and phosphorus (phosphate) were determined using HACH DR 6000 (HACH, Colorado, USA) spectrophotometer (Salicylate TNT Method 10031 and Phosver 3Method 8048). In addition, in Test E, total nitrogen (TN) was also determined using the same spectrophotometer (TNTplus 828 Method 10208).

\section{RESULTS AND DISCUSSION}

Temporal biomass growth profiles in Tests A to E are presented in Fig. 1 and 2. In Test E, the exponential phase was taken as 1-7 days. 


\section{Temperature effect}

Growth rates and the final biomass densities attained at the end of the exponential growth phase with each of the three growth media for the two strains (5587.1 in Tests A and C; and 5572 in Tests B and D) were compared under the two temperature regimes to ascertain if they were a function of temperature. Based on the comparison summarized in Table II, the temperature regimes did not seem to have any significant effect. As such, Test E was conducted at a constant temperature of $40^{\circ} \mathrm{C}$.

\section{Media effect}

In the case of 5587.1 at $40^{\circ} \mathrm{C}$ (Test A), initially the growth rate was highest in the run with supplemented glucose (Code 2), followed by the control (Code 1), and with primary effluent (Code 3). However, after the exponential growth phase, growth with primary effluent (Code 3) overtook the other two and reached $2.77 \mathrm{~g} \mathrm{~L}^{-1}$, while growth in the other two saturated around $1.6 \mathrm{~g} \mathrm{~L}^{-1}$. Similar pattern was observed in Test $\mathrm{C}$ as well, under variable temperature conditions. The initial stimulation of growth with glucose (Code 2) in both temperature regimes is attributed to the heterotrophic nature of the 5587.1 strain.

In the case of strain 5572, growth mediums with supplemented glucose (Code 2) and primary effluent (Code 3) showed similar growth patterns in both Tests B and D for the first 6 days and at the end of the 10 days, growth medium with primary effluent (Code 3 ) showed the highest growth followed by other two mediums (Code 1 and 2). There weren't any apparent growth stimulation in growth at early days in the media with supplemented glucose similar to what observed for 5587.1 in Tests A and C. Overall in all four tests, growth medium with primary effluent (Code 3) showed the highest biomass density at the end of the 10 day experiment.

One possible rationale for the late stage simulation in Code 3 treatments shown in Figure 1 relates to metal ion requirements for growth. Galdieria evolved in hot acidic ground waters expected to contain high concentrations of iron, copper, manganese and zinc. It is hard to rule out the possibility that Galdieria does not require high-affinity transport systems for metal ion co-factors in its natural habitat. If true, laboratory growth in ultra-pure water and 
media chemicals might not provide sufficient trace metals, particularly at higher cell densities. The municipal wastewater would be expected to have higher levels of physiologically important metals and may be responsible for the observed stimulation at late stage cell densities.

Tests A to D indicated favorable growth in autoclaved wastewater; in the case of strain 5587.1 , some evidence of mixotrophy was noted. Therefore, Test E was designed to check the growth patterns of 5587.1 with filter sterilized (similar to growth medium Code 3, in tests A-D; but instead of autoclaving the primary effluent, the sample was filter sterilized) wastewater and non-autoclaved primary effluent. The objective of this experiment was to check the suitability of primary effluent as growth medium for strain 5587.1.

\section{Strain effect}

Comparing the results of Tests A-D, strain 5587.1 exhibited better growth than 5572 under both temperature regimes; after 7-8 days growth in mediums in all four tests started to flatten (except with medium Code 3). It was decided to check whether either $\mathrm{N}$ or $\mathrm{P}$ was limiting the growth. At day 10, all the tubes were transferred to one incubator (temperature kept constant at $40^{\circ} \mathrm{C}$, “constant temperature condition") and combinations of $\mathrm{N}$ and $\mathrm{P}$ were supplemented. The supplementation of nutrients was as follows: 1. in both strains, for two sets of tubes, no nutrient were added; 2. For one set of tubes, $2.64 \mathrm{~g} \mathrm{~L}^{-1}$ of $\left(\mathrm{NH}_{4}\right)_{2} \mathrm{SO}_{4}$ were added; 3. For one set of tubes, $\mathrm{g} \mathrm{L}^{-1}$ of $\mathrm{KH}_{2} \mathrm{PO}_{4}$ was added; 4 . For one set of tubes, $2.64 \mathrm{~g} \mathrm{~L}^{-}$ ${ }^{1}$ of $\left(\mathrm{NH}_{4}\right)_{2} \mathrm{SO}_{4}$ and $0.27 \mathrm{~g} \mathrm{~L}^{-1}$ of $\mathrm{KH}_{2} \mathrm{PO}_{4}$ were added, and the OD values were observed for another 6 days. In both strains there were no apparent difference in growth from day 10 to day 16 in any of the growth mediums. It can be concluded that nutrients were not the limiting factors for growth in the latter part of the experiment.

Tests A to D showed that both 5587.1 and 5572 can be grown in primary effluent and achieve similar growth values compared to standard cyanidium media. There was some growth stimulation in the glucose set with strain 5587.1. Since the growth in tests A and C flattened after 7-8 days, Test $\mathrm{E}$ was designed to validate the results of Tests $\mathrm{A}$ and $\mathrm{C}$ and to the check $\mathrm{N}$ and $\mathrm{P}$ removal in 7 days. 
Nutrient levels in the modified cyanidium media (560 ppm of $\mathrm{N}-\mathrm{NH}_{3}$ and $190 \mathrm{ppm}$ of $\mathrm{P}$ ) are higher than the levels in primary effluent (40 ppm of $\mathrm{N}^{-\mathrm{NH}_{3}}$ and $10 \mathrm{ppm}$ of $\mathrm{P}$ ); in Test $\mathrm{E}$, nutrient level in media Code 4 was adjusted to $40 \mathrm{ppm}$ of $\mathrm{N}-\mathrm{NH}_{3}$ and $10 \mathrm{ppm}$ of $\mathrm{P}$ to maintain similar levels as filter sterilized (Code 5) and non-autoclaved primary effluent (Code 6). Temporal biomass growth profiles in Test $\mathrm{E}$ are presented in Fig. 2a. In this test for 5587.1, 1-7 day OD values were used to calculate the growth rate. Strain 5587.1 showed a decline in OD values at day 1 and then started to grow from day 2 . In terms of growth rate, growth mediums with filter sterilized (Code 5) and non-autoclaved primary effluent (Code 6) showed similar values; $0.186 \pm 0.010$ and $0.175 \pm 0.028 \mathrm{~g} \mathrm{~L}^{-1} \mathrm{~d}^{-1}$ respectively. Strain 5587.1 grew well in the wastewater mediums (Codes 5 and 6) compared to $0.134 \pm 0.010 \mathrm{~g} \mathrm{~L}^{-1} \mathrm{~d}^{-1}$ in modified cyanidium media (Code 4).

Overall, Tests A to D showed that both 5587.1 and 5572 can be grown in primary effluent and achieve similar growth values compared to standard cyanidium media. Also strain 5587.1 showed both autotrophic and heterotrophic growth, but there was no conclusive evidence to conclude the strain as true mixotrophic. In a previous study [18] with $G$. sulphuraria, it was concluded that true mixotrophy does not occur in G. sulphuraria. In test E, Strain 5587.1 showed the potential of using primary effluent as a growth medium.

\section{$N$-removal}

Temporal $\mathrm{NH}_{4}-\mathrm{N}$ profiles in Test $\mathrm{E}$ are shown in Fig. 2b. In Test $\mathrm{E}$ (for strain 5587.1), N$\mathrm{NH}_{3}$ removal rates for 0-7 days were: Code 4-99.71\%; Code 5-95.20\%; Code 6 99.42\%. In addition to the $\mathrm{NH}_{4}-\mathrm{N}$ measurements, total $\mathrm{N}$ (TN) was also measured at the same time points. These measurements were performed to check for uptake of any organic nitrogen $\left(\mathrm{TN}-\mathrm{NH}_{4}-\mathrm{N}=\right.$ organic nitrogen) in the two wastewater mediums (Code 5 and 6 ) during the late stages of the experiment. But as shown in Fig 2, there weren't any evidence of organic nitrogen uptake by 5587.1. The biomass yield per unit $\mathrm{N}$ removed were $39.5 \mathrm{~g} \mathrm{~g}$ ${ }^{1}$ and $35.3 \mathrm{~g} \mathrm{~g}^{-1}$ for media Codes 5 and 6 , respectively. This value is higher than the theoretically calculated yield of $15.8 \mathrm{~g}$ biomass per $\mathrm{g} \mathrm{N}$ removed [14], [13]. The removal 
rates of ammoniacal nitrogen were as follows: for filter sterilized primary effluent: $4.70 \mathrm{mg}$ $\mathrm{L}^{-1} \mathrm{~d}^{-1}$; for non-autoclaved effluent: $4.97 \mathrm{mg} \mathrm{L}^{-1} \mathrm{~d}^{-1}$.

\section{P-removal}

Temporal P- profiles in Test E are shown in Fig. 2c. In Test E (for strain 5587.1), phosphate removal rates for 0-7 days were: Code 4-99.9\%; Code 5-96.10\%; Code 6-97.8\%. The removal rates of phosphate were as follows: for filter sterilized primary effluent: $1.68 \mathrm{mg} \mathrm{L}$ ${ }^{1} \mathrm{~d}^{-1}$; for non-autoclaved primary effluent: $1.47 \mathrm{mg} \mathrm{L}^{-1} \mathrm{~d}^{-1}$. Strain 5587.1 showed highly favorable removal rates for both nitrogen and phosphate in 7 days.

\section{CONCLUSION}

The results of this study showed that the two strains of G. sulphuraria (5587.1 and 5572) are capable of growing in primary effluent at growth rates compare to that in the baseline Cyanidium media. Based on the growth curves, strain 5587.1 appears to be capable of autotrophic and heterotrophic growth in primary effluent. High biomass yield and efficient nutrient removals (of $>95 \%$ of N and $>96 \%$ of $\mathrm{P}$ ) in Test E suggest that G. sulphuraria CCMEE 5587.1 holds promise for efficient nutrient removal from urban wastewaters.

\section{ACKNOWLEDGMENT}

This study was supported in part by the NSF Engineering Research Center, ReNUWIT; the US Department of Energy under contract DE-EE0003046 awarded to the National Alliance for Advanced Biofuels and Bioproducts; the National Science Foundation award \#IIA1301346; and the Ed \& Harold Foreman Endowed Chair.

\section{REFERENCES}

[1] I. T. D. Cabanelas, Z. Arbib, F. A. Chinalia, C. O. Souza, J. A. Perales, P. F. Almeida, et al., "From waste to energy: Microalgae production in wastewater and glycerol," Applied Energy, vol. 109, pp. 283-290, Sep 2013.

[2] A. F. Clarens, E. P. Resurreccion, M. A. White, and L. M. Colosi, "Environmental Life Cycle Comparison of Algae to Other Bioenergy Feedstocks," Environmental Science \& Technology, vol. 44, pp. 1813-1819, Mar 2010. 
[3] "Municipal Nutrient Removal Technologies Reference Document, U.S. Environmental Protection Agency., EPA 832-R-08-006," vol. 2, ed, 2008.

[4] E. S. Heidrich, T. P. Curtis, and J. Dolfing, "Determination of the Internal Chemical Energy of Wastewater," Environmental Science \& Technology, vol. 45, pp. 827-832, Jan 2011.

[5] P. L. McCarty, J. Bae, and J. Kim, "Domestic Wastewater Treatment as a Net Energy Producer-Can This be Achieved?," Environmental Science \& Technology, vol. 45, pp. 7100-7106, Sep 2011.

[6] W. J. Oswald, H. B. Gotaas, C. G. Golueke, W. R. Kellen, E. F. Gloyna, and E. R. Hermann, "Algae in Waste Treatment [with Discussion]," Sewage and Industrial Wastes, vol. 29, pp. 437-457, 1957.

[7] J. P. Hoffmann, "Wastewater treatment with suspended and nonsuspended algae," Journal of Phycology, vol. 34, pp. 757-763, Oct 1998.

[8] S. Chinnasamy, A. Bhatnagar, R. W. Hunt, and K. C. Das, "Microalgae cultivation in a wastewater dominated by carpet mill effluents for biofuel applications," Bioresource Technology, vol. 101, pp. 3097-3105, May 2010.

[9] W. J. Oswald, "The Coming Industry of Controlled Photosynthesis," American Journal of Public Health, vol. 52, pp. 235-242, 1962.

[10] W. J. Oswald, "Microalgae and waste-water treatment. ," in Micro-algal Biotechnology, M. B. L. Borowitzka, Ed., ed Cambridge: Cambridge University Press, 1988, pp. pp. 305-328.

[11] W. J. Oswald, "My sixty years in applied algology," Journal of Applied Phycology, vol. 15, pp. 99-106, 2003.

[12] R. E. Speece, Anaerobic Biotechnology for Industrial Wastewaters. Tennessee: Archae Press, 1996.

[13] A. C. Redfield, B. H. Ketchum, and F. A. Richards, The influence of organisms on the composition of sea-water, 1963.

[14] J. M. Ebeling, M. B. Timmons, and J. J. Bisogni, "Engineering analysis of the stoichiometry of photoautotrophic, autotrophic, and heterotrophic removal of ammonia-nitrogen in aquaculture systems," Aquaculture, vol. 257, pp. 346-358, Jun 2006. 
[15] J. A. Toplin, T. B. Norris, C. R. Lehr, T. R. McDermott, and R. W. Castenholz, "Biogeographic and phylogenetic diversity of thermoacidophilic Cyanidiales in Yellowstone National Park, Japan, and New Zealand," Applied and Environmental Microbiology, vol. 74, pp. 2822-2833, May 2008.

[16] W. Gross, I. Heilmann, D. Lenze, and C. Schnarrenberger, "Biogeography of the Cyanidiaceae (Rhodophyta) based on 18S ribosomal RNA sequence data," European Journal of Phycology, vol. 36, pp. 275-280, Aug 2001.

[17] R. A. Andersen, Algal Culturing Techniques Burlington, MA: Elsevier Academic Press, 2005.

[18] C. Oesterhelt, E. Schmalzlin, J. M. Schmitt, and H. Lokstein, "Regulation of photosynthesis in the unicellular acidophilic red alga Galdieria sulphuraria," Plant Journal, vol. 51, pp. 500-511, Aug 2007. 
Table I. Experimental conditions

\begin{tabular}{|c|c|c|c|c|}
\hline Test & $\begin{array}{c}\text { Temperature } \\
{\left[{ }^{\circ} \mathrm{C}\right]}\end{array}$ & Strain & Code & Growth medium \\
\hline \multirow[t]{3}{*}{$\mathrm{A}$} & 40 & 5587.1 & 1 & $\mathrm{CM}^{\mathrm{a}}$ \\
\hline & & & 2 & $\mathrm{CM}^{\mathrm{a}}+20 \mathrm{mM}$ glucose \\
\hline & & & 3 & $\mathrm{CM}^{\mathrm{b}}$ \\
\hline \multirow[t]{3}{*}{ B } & 40 & 5572 & 1 & $\mathrm{CM}^{\mathrm{a}}$ \\
\hline & & & 2 & $\mathrm{CM}+20 \mathrm{mM}$ glucose \\
\hline & & & 3 & $\mathrm{CM}^{\mathrm{b}}$ \\
\hline \multirow[t]{3}{*}{$\mathrm{C}$} & $26-42$ & 5587.1 & 1 & $\mathrm{CM}^{\mathrm{a}}$ \\
\hline & & & 2 & $\mathrm{CM}+20 \mathrm{mM}$ glucose \\
\hline & & & 3 & $\mathrm{CM}^{\mathrm{b}}$ \\
\hline \multirow[t]{3}{*}{$\mathrm{D}$} & $26-42$ & 5572 & 1 & $\mathrm{CM}^{\mathrm{a}}$ \\
\hline & & & 2 & $\mathrm{CM}+20 \mathrm{mM}$ glucose \\
\hline & & & 3 & $\mathrm{CM}^{\mathrm{b}}$ \\
\hline \multirow[t]{3}{*}{$\mathrm{E}$} & 40 & 5587.1 & 4 & $\mathrm{CM}^{\mathrm{c}}+40 \mathrm{ppm} \mathrm{N}^{\mathrm{f}}+10 \mathrm{ppm} \mathrm{P}^{\mathrm{g}}$ \\
\hline & & & 5 & $\mathrm{CM}^{\mathrm{d}}$ \\
\hline & & & 6 & $\mathrm{CM}^{\mathrm{e}}$ \\
\hline
\end{tabular}

a - Modified Cyanidium Medium (MCM), prepared with sterilized DI water

b - MCM, prepared with autoclaved primary effluent

c - MCM with no N \& P, prepared with sterilized DI water

d - MCM with no N \& P, prepared with filter sterilized primary effluent

e - MCM with no N \& P, prepared with non-autoclaved primary effluent

f - Nitrogen as $\left(\mathrm{NH}_{4}\right)_{2} \mathrm{SO}_{4}$

g - Phosphate as $\mathrm{KH}_{2} \mathrm{PO}_{4}$ 
Table II. Summary of growth rates in Tests A to D

\begin{tabular}{lccc}
\hline Strain & Code & \multicolumn{2}{c}{ Growth rate ${ }^{\mathrm{a}}\left[\mathrm{g} \mathrm{L}^{-1} \mathrm{~d}^{-1}\right]$} \\
\hline 5587.1 & 1 & $0.250 \pm 0.058^{\mathrm{b}}$ & $0.208 \pm 0.041^{\mathrm{b}}$ \\
& 2 & $0.344 \pm 0.022^{\mathrm{b}}$ & $0.291 \pm 0.006^{\mathrm{b}}$ \\
& 3 & $0.257 \pm 0.014^{\mathrm{c}}$ & $0.344 \pm 0.007^{\mathrm{c}}$ \\
& & & \\
& & Test B & Test D \\
\cline { 3 - 4 } 5572 & 1 & $0.156 \pm 0.022^{\mathrm{d}}$ & $0.173 \pm 0.041^{\mathrm{d}}$ \\
& 2 & $0.224 \pm 0.019^{\mathrm{e}}$ & $0.203 \pm 0.001^{\mathrm{d}}$ \\
& 3 & $0.311 \pm 0.004^{\mathrm{d}}$ & $0.374 \pm 0.001^{\mathrm{d}}$
\end{tabular}

${ }^{a}$ Growth rates during exponential growth phase

${ }^{\mathrm{b}}$ Growth rates were calculated using day 0-4 data

${ }^{\mathrm{c}}$ Growth rates were calculated using day 0-10 data

${ }^{\mathrm{d}}$ Growth rates were calculated using day 1-10 data

${ }^{\mathrm{e}}$ Growth rates were calculated using day 1-6 data 

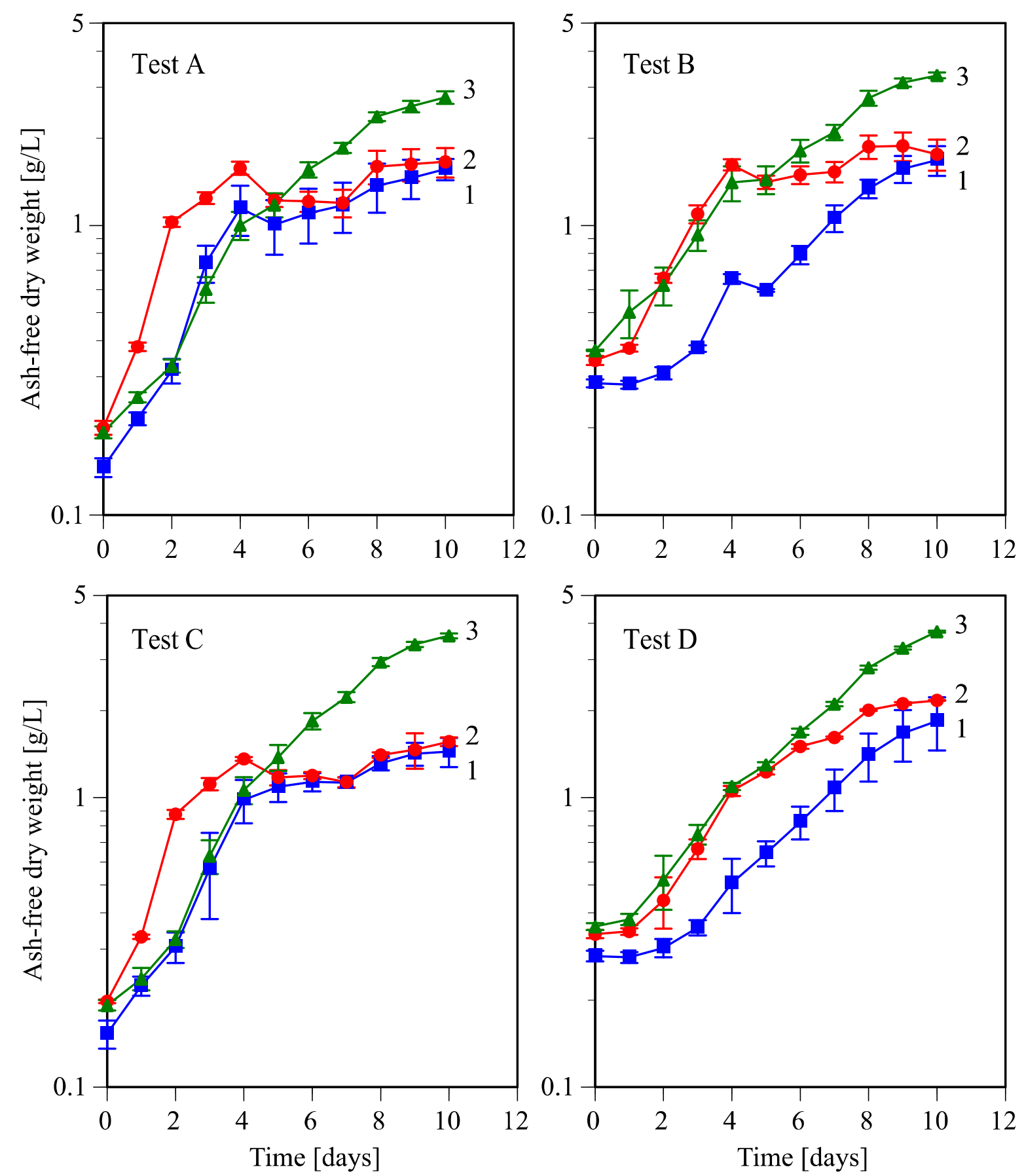

Figure 1. Temporal profiles of biomass growth in Tests A to D.

Numbers represent Codes defined in Table I. Error bars indicate std. dev. from triplicates. 

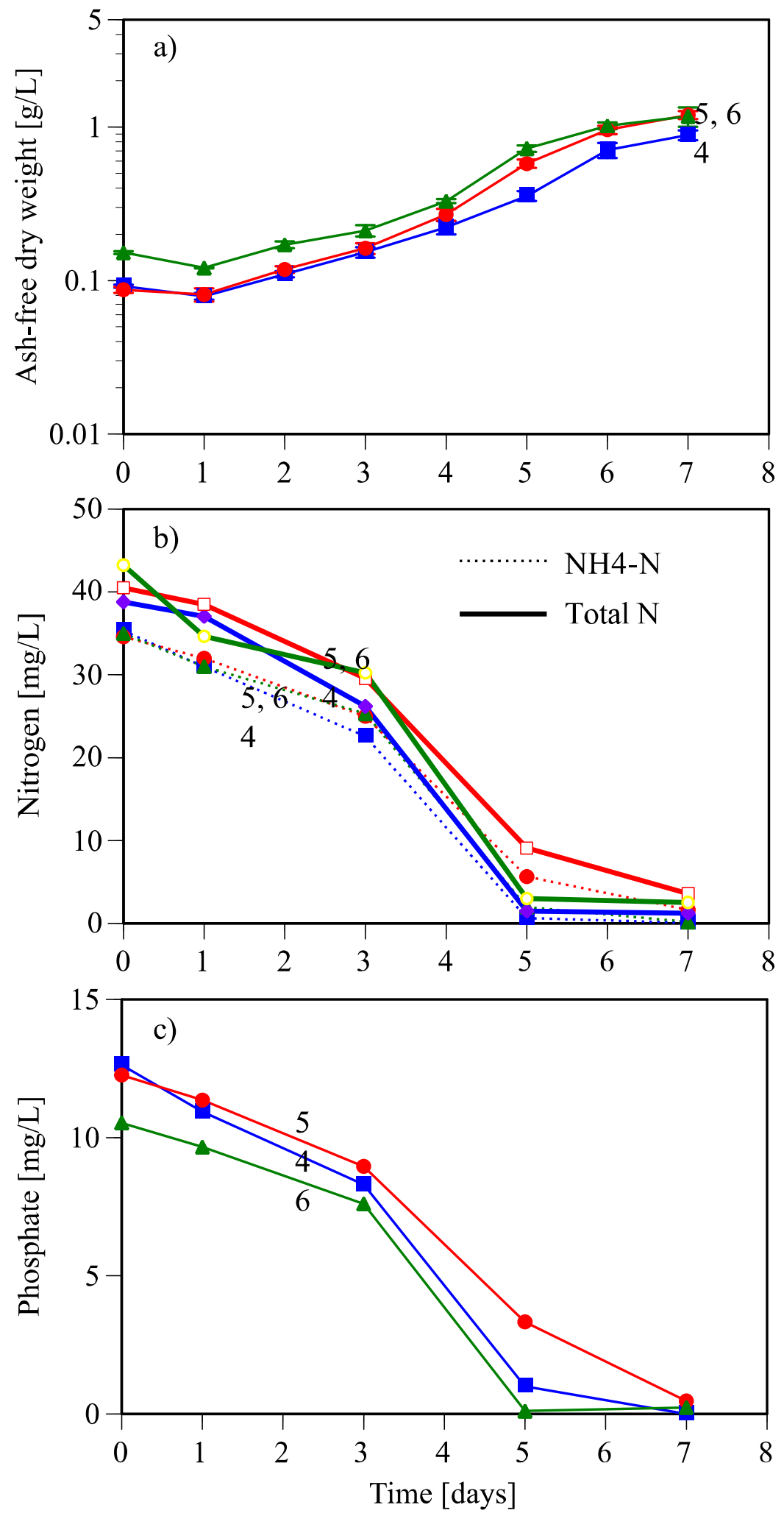

Figure 2. Temporal profiles of biomass growth (a), nitrogen (b), and phosphate (c) in Test E. Numbers represent Codes defined in Table I. 
Species: $\mathbf{5 5 8 7 . 1}$

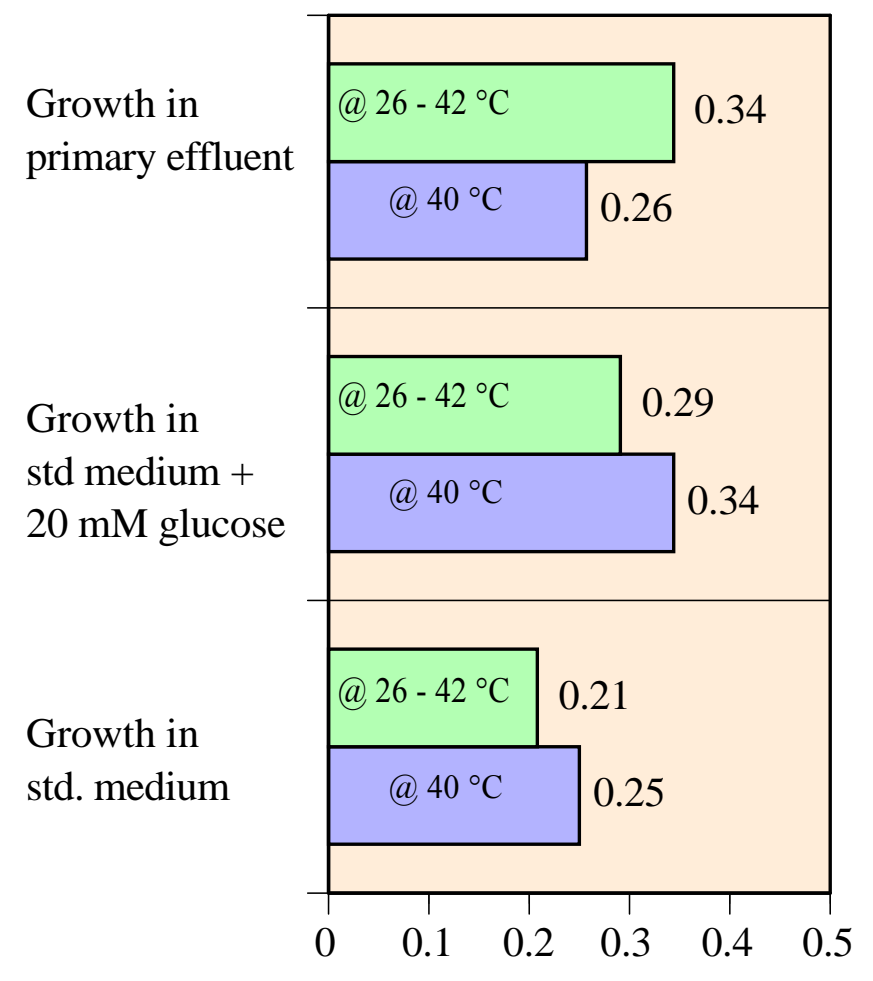

Species: $\mathbf{5 5 7 2}$

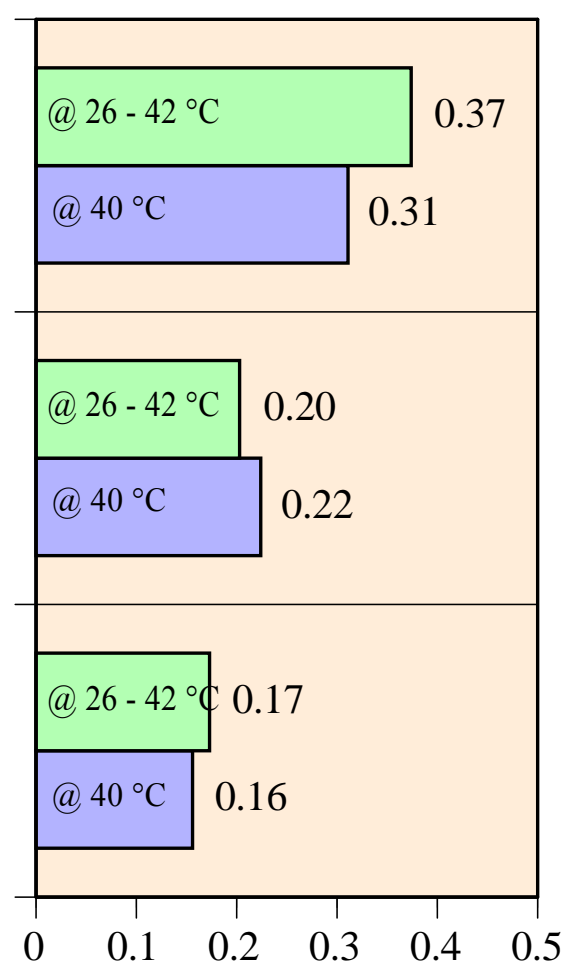

Growth rate [g ash-free dry weight/L-d] 